\title{
Gestión del agua y minería en el Perú: manejo del agua en operaciones mineras e intervenciones en la cuenca
}

\author{
Ángel Espinar Álvarez*
}

\begin{abstract}
Over the last years the mining industry has been performing its activities under conditions in which access and use of water resources is not just vital for miningmetallurgical processes, but also a key factor in order to be accepted as a fellow actor in the basin, precisely by those it has to enter into agreements with, not just for shared use, but also for shared management, based on technical and regulatory procedures, set forth by the competent water authority. Common understanding and agreement about water availability within a certain geographical area, overseen by the regulatory intervention of the statutory authority, in line with water demand, is the way to build water resources governability in the basin, the geographical space where integrated water management efforts are to be conducted.

There is widespread consensus among the majority of water-consuming economic activities, mining in particular, about the need to incorporate a vision and focus on integrated water management, in order to ensure its conservation, quality and rational use. The mining industry is determined to show its activities and water management efforts, inside and outside its facilities, make a positive contribution to sustainable development, environmental protection, and specifically to the stewardship of water resources in those basins where it operates, aiming at undertaking its activities in a responsible manner.
\end{abstract}

Key words: Integrated water management, water management, water management organizations.

* Magíster en Antropología de la Pontificia Universidad Católica del Perú (PUCP) con estudios en Gestión Integrada de Recursos Hídricos de la Confederación Iberoamericana del Agua, Uruguay. Actualmente se desempeña como Jefe de Gestión de Recursos Hídricos en Compañía de Minas Buenaventura S.A.A., correo electrónico: angesalva@hotmail.com 


\section{Resumen}

En los últimos años, la industria minera viene desarrollando sus actividades en escenarios en los que el acceso y uso del agua constituye no sólo un recurso con el cual realizan los procesos minero-metalúrgicos, sino también un factor determinante para situarse como actor junto con otros en la cuenca, con quienes tiene que establecer acuerdos no sólo de uso sino también de gestión compartida, sobre la base de procedimientos técnico-normativos que señala la autoridad competente en materia de recursos hídricos. La concurrencia y acuerdo por las disponibilidades hídricas de un territorio hidrográfico determinado mediada por la intervención regulatoria de la autoridad en la atención de las demandas hídricas, construye gobernabilidad en torno a los usos de los recursos hídricos en la cuenca, espacio privilegiado para realizar la gestión integrada del agua.

En la mayoría de las actividades productivas que usan agua y específicamente en la minería, existe consenso sobre la necesidad de incorporar como visión y enfoque una gestión integrada del recurso hídrico para asegurar su conservación, calidad y uso racional. La industria minera está empeñada en demostrar que sus actividades, especialmente el manejo de las aguas dentro y fuera de sus operaciones, contribuyen con el desarrollo sostenible, la protección del medio ambiente y específicamente de los recursos hídricos en las cuencas donde se ubican sus actividades, desarrollando sus operaciones en forma responsable para respetar y proteger su entorno.

Palabras clave: gestión integrada de recursos hídricos, manejo de aguas, organización de gestión de recursos hídricos.

\section{Minería y demanda de agua en el Perú}

Es conocido en el Perú, en el único estudio disponible del año 1992, que la demanda general de agua de los principales diversos usos consuntivos, como puede apreciarse en la Figura 1, indican que la minería es el sector productivo que menos agua consume, aunque no siempre esta proporción es percibida como insignificante en los territorios hidrográficos de escala menor (microcuencas, subcuencas), donde las actividades mineras suelen realizar sus actividades.

Podemos contrastar con información de una cuenca específica, la distribución de las demandas hídricas a nivel nacional, donde concurren diversos usos y observar cómo se da la relación entre gestión del agua y la actividad minera. Es importante señalar, que el análisis que se hace toma como referencia los procesos de gestión del agua en una determinada cuenca, sin que por ello se afirme que éste constituye un comportamiento general, dado que cada cuenca posee su propia configuración hidrológica, social y de gestión. Sin embargo, consideramos que los elementos que forman parte del presente análisis permiten establecer conclusiones en torno al 
funcionamiento de la actividad minera respecto a la gestión del recurso hídrico en la cuenca hidrográfica.

\begin{tabular}{lrrrrr}
\hline \multicolumn{2}{c}{ Región hidrográfica } & Agrícola & Poblacional & Minero & Industrial \\
\hline Pacífico & $\left(\mathrm{hm}^{3}\right)$ & 14,200 & 1,018 & 152 & 1,103 \\
Amazonas & $\left(\mathrm{hm}^{3}\right)$ & 1,996 & 228 & 53 & 49 \\
Titicaca & $\left(\mathrm{hm}^{3}\right)$ & 71 & 18 & 2 & 3 \\
\hline Total & $\left(\mathrm{hm}^{3}\right)$ & 16,267 & 1,264 & 207 & 1,155 \\
\hline
\end{tabular}

Fuente: MINAG-DGAS, Estudio básico situacional de los recursos hídricos del Perú, 1992.

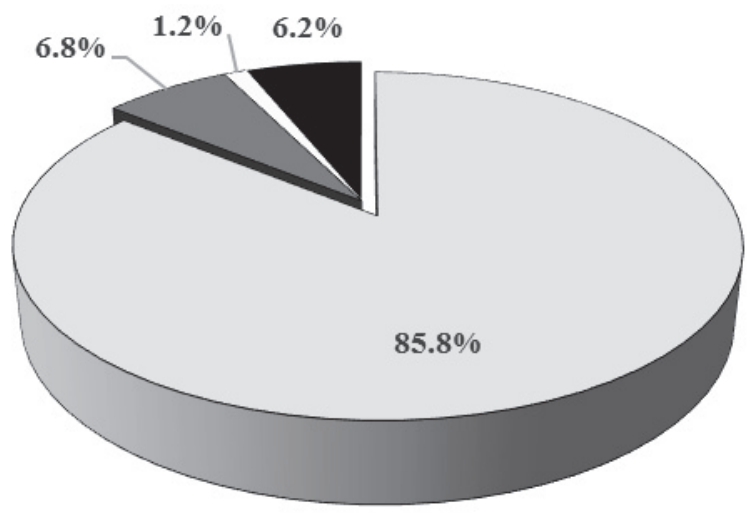

\section{$\square$ Agrario $\square$ Poblacional $\square$ Minero $\quad$ Industrial}

Figura 1. Demandas de agua.

En la cuenca Chancay-Lambayeque, una de las cuencas importantes del norte del Perú, la demanda anual de agua por cada uno de los usos (Figura 2), donde el mayor uso lo tiene el agrícola (93.25\%) y el menor, el minero $(0.08 \%)$. En la parte baja de la cuenca con sistema regulado, las demandas representan un total neto de 1,136.04 millones de metros cúbicos; lo requerido para el uso poblacional es de $48 \mathrm{mmc}(4.23 \%)$; la demanda por el uso agrario es de $1,062.84 \mathrm{mmc}$ y representa el $93.56 \%$ de la demanda total; y por el uso industrial es de $25.20 \mathrm{mmc}$ que representa el $2.22 \%$ del total. En la parte media y alta de la cuenca los usos consuntivos preponderantes son el poblacional, agrario y minero. La demanda para el uso agrario es de $22.45 \mathrm{mmc}$ para el riego complementario de aproximadamente 5,127.68 ha, la de uso poblacional de $4.39 \mathrm{mmc}$ y la de uso minero de $0.93 \mathrm{mmc}$. 


\begin{tabular}{|c|c|c|c|}
\hline \multirow[b]{2}{*}{ Uso } & \multicolumn{3}{|c|}{ Demanda anual $(\mathrm{mmc})$} \\
\hline & Cuenca baja & $\begin{array}{c}\text { Cuenca media } \\
\text { y alta }\end{array}$ & Total \\
\hline Agrario & $1,062.84$ & 22.45 & $1,085.29$ \\
\hline Poblacional $(*)$ & 48.00 & 4.39 & 52.39 \\
\hline Industrial & 25.20 & - & 25.20 \\
\hline Minero & - & 0.93 & 0.93 \\
\hline Total & $1,136.04$ & 27.77 & 1.163 .81 \\
\hline
\end{tabular}

* Cuenca alta estima.

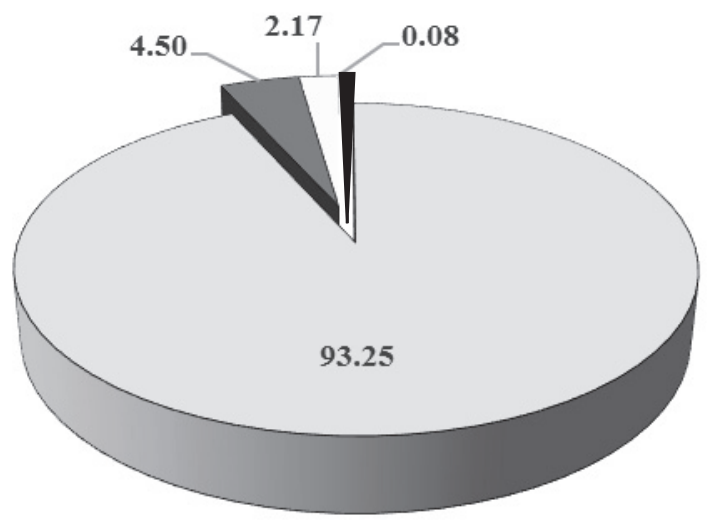

\section{$\square$ Agrario $\square$ Poblacional $\square$ Industrial $\quad$ Minero}

Figura 2. Demanda anual de agua cuenca Chancay-Lambayeque.

Fuente: PMGRH-ANA, 2013.

Es cierto que la demanda de agua del sector minero es puesta en cuestión en territorios donde se percibe la escasez del recurso, y no siempre porque el recurso sea escaso sino porque el acceso de la población a dicho bien, es limitada en contextos donde la infraestructura hidráulica es inexistente para captar las aguas de precipitación que discurren al mar sin que sean aprovechadas oportunamente $(53 \%$ se pierde en la vertiente del Pacífico), o por problemas de eficacia en los usos, especialmente en el agrícola que cuenta con promedios de eficiencia de apenas el $35 \%$, sumado a los problemas ocasionados de salinidad dPe suelos y mal drenaje.

Frente a esta realidad de las demandas hídricas, coexisten las controversias para el funcionamiento de la actividad minera, por lo general en la fase de exploraciones, y que tienen origen en la percepción de la población, aunada a una mayor con- 
ciencia ambiental, de temores frente a posibles efectos de contaminación de las fuentes de agua. Estas percepciones, son generalmente sobredimensionadas por efectismos de determinada forma de hacer política localmente. Se ha investigado poco en torno a las causas profundas de lo que se ha señalado como una "posición antiminera".

El informe reciente de la Oficina de Diálogo y Sostenibilidad, adscrito a la Presidencia de Consejo de Ministros (Willaqniki, núm. 11), señala que:

Los conflictos en entornos mineros expresan las aspiraciones y expectativas de la población por acceder a bienes y servicios públicos, así como a beneficios derivados de la minería. El "sentimiento antiminero" es predominante sólo en una minoría de casos, y por lo general, está asociado a ámbitos donde no existe experiencia directa previa de actividades mineras y las actitudes y prácticas de ciertas empresas agudizaron la desconfianza siendo percibidas por muchos como una amenaza para el acceso a ciertos recursos (agua, tierras).

\section{Conservación y uso de agua en área de influencia minera}

El acceso y uso del agua en los entornos mineros constituye una de las políticas centrales de responsabilidad ambiental y social de la industria minera, y busca responder a esta problemática o necesidad a través de la construcción de infraestructura hidráulica que permita captar o embalsar agua generada en las temporadas de mayor precipitación que permitan afrontar los tiempos de estiaje y contribuir con el acceso de agua de otros usos ubicados en las partes media o baja de la cuenca.

La actividad minera en sus operaciones adopta mecanismos de conservación del agua, que tienen que ver con la gestión de la cantidad y su acceso. ${ }^{1}$ Uno de estos es el aporte a la regulación del recurso hídrico en la parte alta de la cuenca, donde generalmente se ubica la mina, en función de las demandas existentes en el entorno de las operaciones. El represamiento y embalse del agua constituye uno de los mecanismos que la industria minera asume como prioridad en su política ambiental, como forma de mejorar la disponibilidad hídrica en el entorno de las futuras operaciones, y como política de responsabilidad social frente a las necesidades y demandas de otros usos en la cuenca.

Los estudios de impacto ambiental (EIA) contienen información relevante de la hidrografía, hidrología e hidrogeología de la llamada área de influencia y cons-

1 El acceso al agua es un derecho fundamental del ser humano, y en Buenaventura estamos convencidos que para desarrollar todo proyecto $-\mathrm{y}$ no solo minero sino de cualquier otro sector productivo o de servicios - es imprescindible incorporar el agua como un factor fundamental. Por ello, cuando construimos represas o reservorios lo hacemos para contar con más agua de la que pudiera disponer el proyecto minero, y de esta forma contribuimos a que las poblaciones de nuestro entorno puedan acceder a este recurso. En Benavides Ganoza, Roque, La minería responsable y sus aportes al desarrollo del Perú, Lima, 2012. 
tituyen instrumentos de conocimiento necesarios para el manejo de las aguas en las operaciones mineras en todas sus fases. Esta información es fundamental para contar con los permisos ambientales ${ }^{2}$ necesarios que permitan al proyecto minero entrar en operaciones, y para establecer en la vida del proyecto la demanda de agua necesaria para producir, conjuntamente con la demanda de los otros usos que están en el área de influencia. Es sobre la base de esta información hídrica que se define en el mismo estudio ambiental la implementación de infraestructura hidráulica y las dotaciones de agua para los fines mineros y el respeto a las demandas de otros usos.

Si bien la información de los estudios de impacto ambiental es generada por una entidad privada, ésta es de dominio público por los procesos de consulta ciudadana y porque pasan a formar parte del acervo de información ambiental que aprueba el Estado en sus diferentes instancias. Este tipo de información (hidrología de la cuenca, régimen hidrológico, geomorfología, red hidrográfica, entre otros) no siempre es utilizada en aras de pensar en un mejor aprovechamiento de los recursos hídricos de determinado territorio. También es cierto que las prácticas de poner en público información ambiental no son frecuentes en las entidades privadas, lo cierto es que este tipo de información es pública y está disponible al servicio de la cuenca, y sólo requieren de los mecanismos que gestionen esta información para ponerla al alcance de los usuarios.

Las siguientes presas y embalses (Tabla 1) corresponden a diversas empresas mineras, construidas la mayor parte de ellas en la última década, y como puede observarse los volúmenes acumulados, sólo en los ejemplos mencionados, ascienden a casi $113 \mathrm{mmc}$, destinados principalmente al uso agropecuario, y que posibilitan regular hidrológicamente la cuenca en épocas de estiaje.

El incremento de los caudales en la cuenca son favorecidos por estas obras hidráulicas que permiten retener agua y tenerla disponible para regular la cuenca, y en muchos casos para ser aprovechadas en obras de riego y uso poblacional previamente tratada. Los volúmenes destinados al uso de la actividad minera suelen en muchos casos ser mínimos y en algunos casos no requeribles por los trabajos de recirculación que permiten reusar las aguas tanto en los procesos industriales como en riego de componentes y vías de acceso.

2 Los actuales términos de referencia que propone la autoridad competente en materia hídrica del Perú en la evaluación de los estudios ambientales, contempla que la descripción del proyecto minero en cada una de sus etapas (planificación, diseño, construcción, operación, mantenimiento y abandono o cierre) contenga información relacionada a las demandas actuales de agua, las demandas asociadas a la actividad, la proyección de consumo de agua de la fuente y el balance de agua operacional, además de presentar la disponibilidad considerando el balance hídrico y los otros usos en el área de influencia ( $c f r$. R.J. $\mathrm{N}^{\circ}$ 250-2013-ANA). 
Tabla 1

Presas y embalses en actividades mineras

\begin{tabular}{rllrl}
\hline No. & Embalses & \multicolumn{1}{c}{ Ubicación } & $\begin{array}{r}\text { Cantidad } \\
\text { almacenada } \\
\left(\mathrm{m}^{3} / \text { año }\right)\end{array}$ & \multicolumn{1}{c}{ Uso } \\
\hline 1 & Añil cocha & Oyón, Lima & $8,676,900$ & Uso energético \\
2 & Bramadero & La Zanja, Cajamarca & 512,048 & Uso agrícola y poblacional \\
3 & Corococha & Orcopampa, Arequipa & $5,843,070$ & Uso energético \\
4 & Jinuahuaycco & Breapampa, Ayacucho & 269,034 & Uso minero \\
5 & Lacsacocha & Mallay, Lima & 394,800 & Uso minero y agrícola \\
6 & Patón & Oyón, Lima & $7,487,497$ & Uso energético \\
7 & Pillones & Arequipa & $80,000,000$ & Uso agrícola, minero y poblacional \\
8 & Río Grande & Cajamarca & 400,000 & Uso agrícola y ganadero \\
9 & Río Rejo & Cajamarca & 400,000 & Uso agrícola y ganadero \\
10 & San José & Cajamarca & $6,000,000$ & Uso agrícola y ganadero \\
11 & Chailhuagón & Cajamarca & $2,600,000$ & Uso agrícola y ganadero \\
\hline
\end{tabular}

Fuente: Elaboración propia.

\section{Manejo de aguas en actividades mineras}

Como parte de la política y gestión ambiental, frente a la escasez del recurso hídrico y la creciente demanda en los diversos sectores productivos y usuarios en la cuenca donde se ubican las empresas mineras, éstas vienen implementando mecanismos que contribuyan a la disminución del consumo de agua fresca, el uso eficiente del recurso y el manejo responsable de los acuíferos y ecosistemas a partir de los cuales se abastecen para sus procesos productivos.

La actividad minera genera volúmenes significativos del líquido en sus operaciones que demandan un manejo al interior de la mina, dado que estas aguas entran en contacto con los cuerpos situados en la cuenca. En los últimos años, la producción minera, no sólo por la concurrencia con otros usos que demandan mayores cantidades de agua, ha tenido que optimizar los niveles de consumo, sino por la eficiencia en el manejo de las aguas generadas, propias de la producción minera y cumplimiento de responsabilidades ambientales.

Los estudios ambientales contienen el diseño de las operaciones mineras del que forman parte un conjunto de componentes que están vinculados a la generación de estas aguas, las cuales deben ser debidamente encausadas y tratadas antes de su contacto con el medio ambiente. En el caso de las minas de tajo abierto, por las actividades que suelen realizarse (perforación, voladura, regado de vías, carguío de mineral) se generan aguas ácidas por el contacto de las aguas de precipitación y los 
contenidos metálicos expuestos. Lo mismo sucede con componentes formados con el material de contenido no valioso de mineral, denominado material estéril que en su conjunto forman el depósito de material estéril (DME) y el depósito de material orgánico (DMO) formado con las primeras capas de suelo orgánico que son acumulados para los procesos de revegetación de áreas disturbadas y que se usan en los planes de cierre de la mina.

Los procesos de recirculación, ${ }^{3}$ constituyen en la actividad minera uno de los mecanismos de uso eficiente del recurso hídrico, sobre todo en contextos donde concurren demandas de otros usos y existen niveles de escasez del recurso. Es conocido que los procesos metalúrgicos por flotación son los que requieren mayores volúmenes de agua fresca, con rangos que puede variar entre 1.5 y $3 \mathrm{~m}^{3} /$ ton de mineral tratado, y cuyos volúmenes de recirculación también son mayores. En los casos de procesos de recuperación hidrometalúrgica los niveles de consumo de agua fresca suelen ser menores y los circuitos de recirculación más eficientes, con rangos de 80 a $85 \%$ de recirculación como buena práctica.

En materia de calidad del agua, es importante señalar que los proyectos mineros poseen en sus estudios de impacto ambiental (EIA), requisito previo para el funcionamiento de las operaciones mineras, las caracterizaciones de las aguas que son generadas en los procesos minero-metalúrgicos, los sistemas de tratamientos necesarios, como se aprecia en la Figura 3, para asegurar la calidad de las aguas de modo que no afecten negativamente el medio ambiente, específicamente, los cuerpos naturales de agua. En cumplimiento de la normatividad ambiental vigente en el Perú, la industria minera está obligada a cumplir con los límites máximos permisibles $^{4}$ (LMP), y es fiscalizada en este orden, para el caso de la generación de efluentes producto de los procesos industriales antes de ser emitidos a un cuerpo receptor.

3 El concepto de recirculación comprende la noción de consumo de agua fresca, entendida como la cantidad de agua fresca necesaria para procesar una tonelada de mineral o para obtener $1 \mathrm{~kg}$ de mineral fino o $1 \mathrm{oz}$ de oro, según se trate. El consumo de agua total comprende el agua total necesaria para mantener el régimen productivo, de donde se entiende que la tasa de recirculación es el porcentaje producto de la diferencia (agua total-agua fresca/agua total*100). En general, los requerimientos de agua fresca suelen ser menores a la totalidad de uso en las diferentes etapas del proceso productivo minero, tomando en cuenta que los excedentes de agua de una etapa pueden ser transformados en fuente de abastecimiento de otra etapa, previas consideraciones de cumplimiento normativo ambiental respecto a la cantidad, calidad, o a factores que tienen que ver con la distancia y características de la conducción del recurso y la relación costo-beneficio de su reuso.

4 De acuerdo al D.S. N ${ }^{\circ}$ 010-2010-MINAM, el límite máximo permisible (LMP) es la medida de concentración o el grado de elementos, sustancias o parámetros físicos, químicos y biológicos que caracterizan al efluente líquido de actividades minero-metalúrgicas, y que al ser excedida causa o puede causar daños a la salud, al bienestar humano y al ambiente. Su cumplimiento es exigible por el Ministerio del Ambiente y los organismos que conforman el sistema de gestión ambiental. 


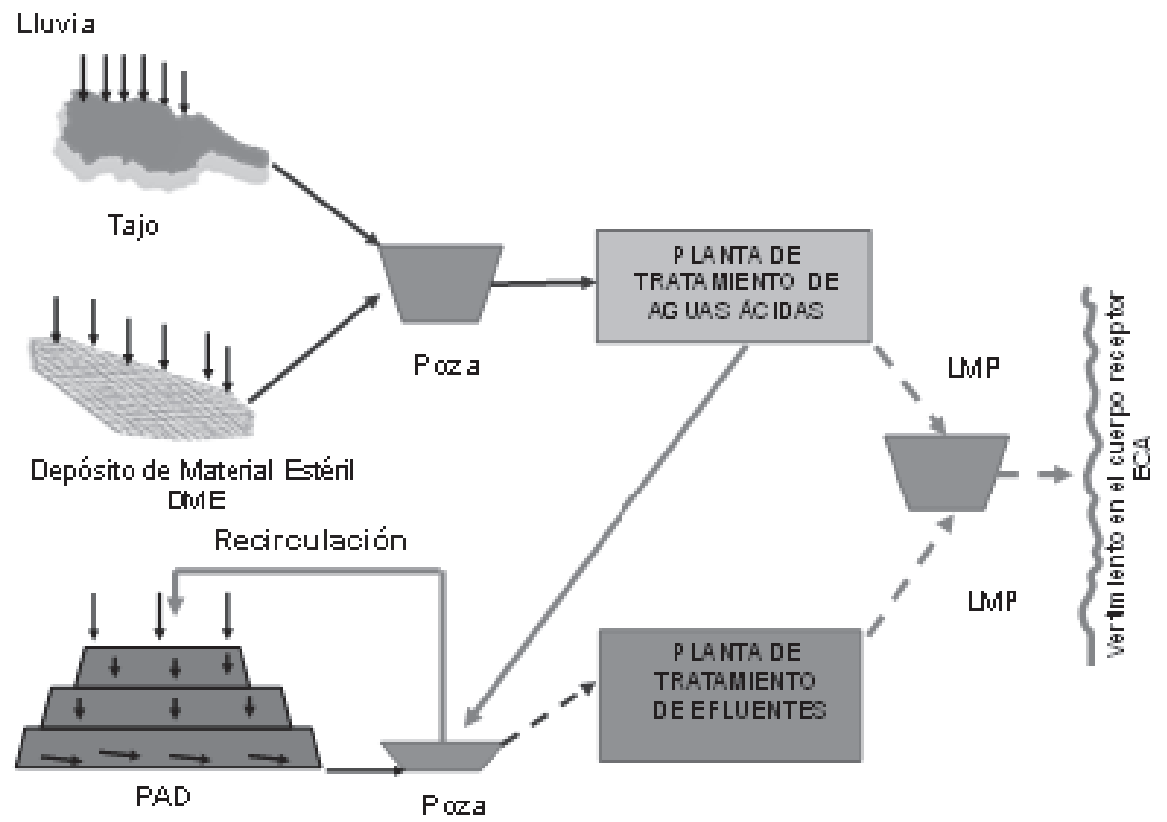

Figura 3. Manejo del agua en la actividad minera.

Del mismo modo, tanto la caracterización de las fuentes naturales de agua que se ubican en la huella del proyecto minero y que forman parte de la línea base ambiental, así como el monitoreo permanente de la calidad de las aguas, constituyen la exigencia ambiental para el cumplimiento de los Estándares de Calidad Ambiental

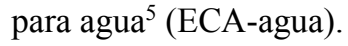

Destacamos los aspectos generativos de aguas al interior de la mina, si bien el concepto de manejo de cuencas (watershed management) dista del ordenamiento ambiental que tienen las operaciones mineras, presenta tales semejanzas en un área de influencia, que generalmente es una microcuenca y tiene sus impactos en la cuenca mayor. A lo mencionado anteriormente, las áreas de influencia comportan además procesos de forestación y reforestación como formas de generar ecosistemas que contribuyan con el ciclo hidrológico, convirtiendo los suelos en especies de esponjas de agua que regulan las descargas y cuyos objetivos están orientados a

5 El D.S. $N^{\circ}$ 002-2008-MINAM, establece que los Estándares de Calidad Ambiental para agua (ECA-agua) establecen el nivel de concentración o el grado de elementos, sustancias o parámetros físico, químicos, biológicos presentes en el agua, en su condición de cuerpo receptor y componente básico de los ecosistemas acuáticos, que no representa riesgo significativo para la salud de las personas y el ambiente. 
contar a la cuenca como captadora de agua para diferentes fines, reducir el impacto de la escorrentía y proteger áreas vulnerables susceptibles de deslizamientos.

\section{Organizaciones de gestión del agua por cuencas}

En el enfoque de gestión integrada de recursos hídricos, las cuencas constituyen las unidades territoriales adecuadas para la gestión del agua. Como señala Dourojeanni,

...son las principales formas terrestres dentro del ciclo hidrológico que captan y concentran la oferta del agua que proviene de las precipitaciones. Además de esta condición física y biológica básica, cabe mencionar por lo menos las siguientes razones que explican este hecho. La principal es que las características físicas del agua generan un grado extremadamente alto, y en muchos casos imprevisible, de interrelación e interdependencia (externalidades o efectos externos) entre los usos y usuarios de agua en una cuenca. Las aguas superficiales y subterráneas, sobre todo ríos, lagos y fuentes subterráneas, así como las cuencas de captación, las zonas de recarga, los lugares de extracción de agua, las obras hidráulicas y los puntos de evacuación de aguas servidas, incluidas las franjas costeras, forman, con relación a una cuenca, un sistema integrado e interconectado (2002:8).

Esta interrelación e interdependencia entre los usos y los usuarios requieren de dos niveles de gestión: una organización de recursos hídricos de cuenca que reúna a los representantes de los principales actores y usuarios del agua y un organismo de recursos hídricos de cuenca que de soporte técnico a las decisiones de la organización. En el caso del Perú, de acuerdo a la Ley de Recursos Hídricos aprobada en el año 2009 (Ley N²9338), esta organización de gestión se denomina Consejo de Recursos Hídricos de Cuenca (CRHC) ${ }^{6}$ y el organismo de gestión, Secretaría Técnica.

La representación de los diversos usuarios del agua en la cuenca, del Estado, comunidades y sociedad civil en este espacio de coordinación, concertación y de planificación de los recursos hídricos, tiene una configuración reglamentada, cuya conformación sigue un proceso eleccionario para los casos de los usuarios que son titulares de derechos de uso de agua y de designación para la representación estatal.

6 El Consejo de Recursos Hídricos de Cuenca es un órgano de naturaleza permanente, integrante de la Autoridad Nacional del Agua, creado mediante el Decreto Supremo N ${ }^{\circ}$ 008-2011-AG, refrendado por el presidente del Consejo de Ministros y el ministro de Agricultura a iniciativa de los gobiernos regionales, pudiendo ser regional o interregional. La finalidad del Consejo de Recursos Hídricos es lograr la participación activa y permanente de los gobiernos regionales, gobiernos locales, sociedad civil, organizaciones de usuarios de agua, comunidades campesinas, comunidades nativas y demás integrantes del Sistema Nacional de Gestión de los Recursos Hídricos que intervienen en la cuenca, con el objeto de participar en la planificación, coordinación y concertación para el aprovechamiento sostenible de los recursos hídricos en sus respectivos ámbitos, mediante el Plan de Gestión de Recursos Hídricos en la Cuenca. 
La conformación del CRHC implica una representación por región presente en la cuenca (véase Figura 4).

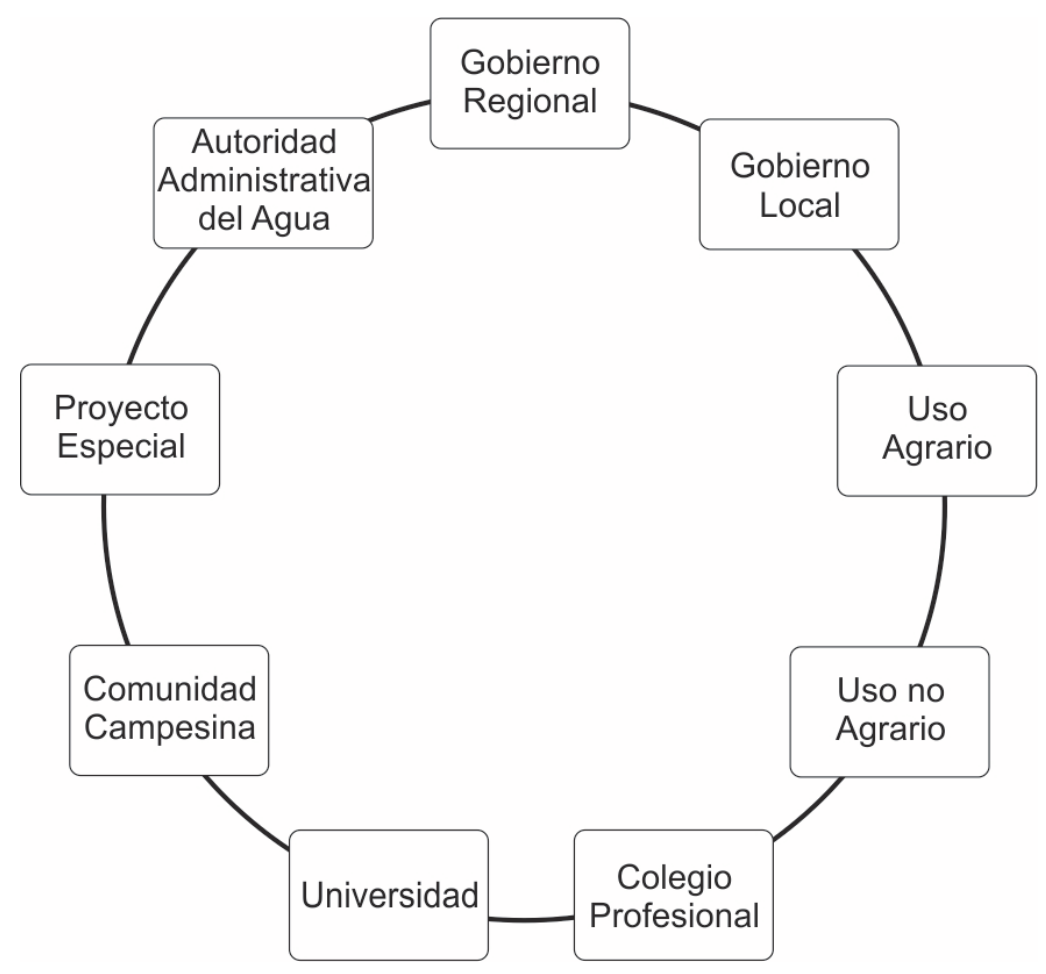

Figura 4. Representantes del Consejo de Recursos Hídricos de Cuenca.

Las experiencias recientes de creación de los Consejos de Recursos Hídricos de Cuenca (CRHC) en el Perú abarcan las cuencas del Chira Piura, ChancayLambayeque, Chancay Huaral, Chili y Tumbes, que han sido promovidas por la Autoridad Nacional del Agua y creadas a propuesta de los gobiernos regionales ubicados en estas cuencas. En un primer tiempo los Consejos de Recursos Hídricos de Cuenca han venido funcionando orientados a elaborar los planes de gestión de recursos hídricos y evaluar la calidad de los recursos hídricos en los ámbitos de sus cuencas respectivas, y con el apoyo técnico y financiero de la cooperación multilateral (Banco Mundial — BM, Banco Interamericano de Desarrollo — BID), y muy recientemente cuentan con sus secretarías técnicas ${ }^{7}$ respectivas.

$7 \quad$ Según el Reglamento de la Ley de Recursos Hídricos, en su artículo 30 y 31, señala que la Secretaría Técnica desarrolla y ejecuta las labores técnicas que permiten el adecuado funcionamiento del Consejo de Recursos Hídricos de Cuenca. Está a cargo de un Secretario Técnico designado por concurso 
Estos procesos de gestión del agua por cuencas tienen un pilar importante en estas organizaciones pero requieren aún ser cimentadas sobre la base de un conocimiento directo de la realidad de la cuenca, de un reconocimiento del carácter multisectorial que tiene la gestión del agua y de los diversos usos y usuarios de este recurso. En ese sentido, la participación de las empresas mineras en la representación de los usos "no agrarios", si bien aún es poca como pocos son los consejos creados, éstas procuran que sus instituciones sean reconocidas como un actor relevante en los procesos de concertación y decisión respecto a la definición de los diagnósticos y propuestas de aprovechamiento sostenible del agua en la cuenca. Al mismo tiempo, para las mismas empresas, su participación les ha permitido incorporar en sus políticas y objetivos socio-ambientales y de operaciones, la visión integrada de la cuenca, aportar a ésta en términos de calidad y cantidad de agua y proyectar sus propias actividades en el conjunto de los procesos de ordenamiento del territorio y de gestión del agua. En suma, generar más confianza para sus propias actividades.

La participación del uso minero en los CRHC creados en el Perú, se da en los casos de la cuenca Chili en Arequipa y de la cuenca Chancay-Lambayeque, en Cajamarca y Lambayeque. Para el efecto del análisis nos remitiremos a este último caso con el propósito de establecer algunos criterios de lectura que nos permitan comprender estos procesos en gestación.

La cuenca hidrográfica del río Chancay-Lambayeque (Figura 5) está ubicada en la costa norte del Perú y constituye una de las cuencas más importantes de la vertiente de Pacífico. Geográficamente, se encuentra ubicada entre los paralelos $06^{\circ}$ $21^{\prime} 12^{\prime \prime}$ y $06^{\circ} 57^{\prime}$ 09” latitud Sur, y $80^{\circ} 10^{\prime} 39^{\prime}$ y $78^{\circ} 32$ ' 17" longitud Oeste. Políticamente abarca parte de las regiones de Lambayeque y Cajamarca. En cuanto a la región de Lambayeque, abarca parte de sus tres provincias (Chiclayo, Lambayeque y Ferreñafe) y en el caso de Cajamarca cuatro de sus provincias (Chota, Santa Cruz, San Miguel y Hualgayoc).

La conformación del CRHC Chancay-Lambayeque, de carácter interregional por abarcar geográficamente las regiones de Lambayeque y Cajamarca, se fundamenta en los "Lineamientos generales para la creación de los Consejos de Recursos Hídricos de Cuenca", emitidos por la Autoridad Nacional del Agua en 2011, en el cual se señala los criterios que orientan la conformación y creación de consejos de recursos hídricos de cuencas, de acuerdo al siguiente proceso:

público de méritos convocado por la Jefatura de la Autoridad Nacional del Agua, conforme a Ley. La secretaría técnica ejercerá, con conocimiento del Presidente y dando cuenta al Consejo de Recursos Hídricos de Cuenca, las funciones señaladas en los literales f), g), h) e i) del artículo 31 del Reglamento (como hacer cumplir el Plan de Gestión, emitir opinión, instruir procedimientos administrativos de reuso, vigilancia y monitoreo de calidad del agua). 


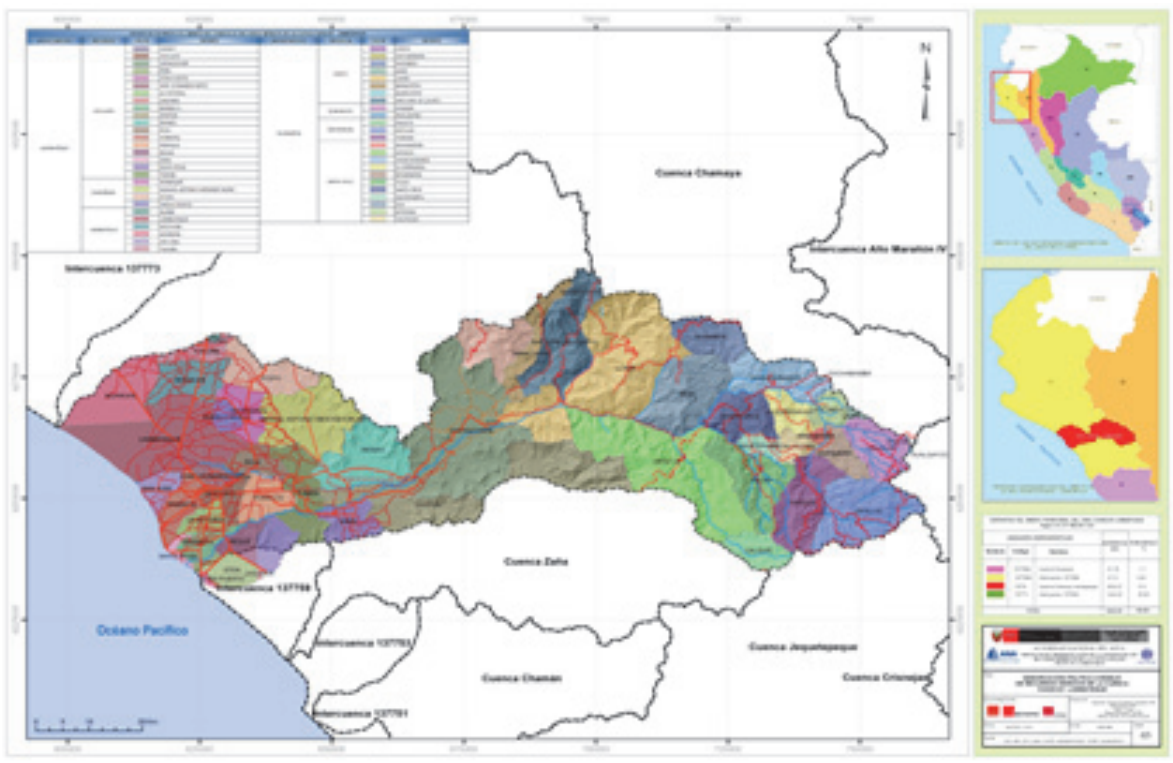

Figura 5. Cuenca Chancay Lambayeque.

Fuente: PMGRH-ANA, 2013.

- Preparación y coordinación interinstitucional

- Caracterización general de la cuenca e identificación de actores

- Conformación y acreditación de representantes

- Preparación del expediente de creación

A iniciativa de los gobiernos regionales de Lambayeque y Cajamarca se creó el CRHC de la cuenca Chancay-Lambayeque, mediante Decreto Supremo $\mathrm{N}^{\circ}$ 008-2011-AG el 9 de julio del año 2011, instalándose el 25 de julio del 2011 en la ciudad de Cajamarca. Este Consejo está conformado por 16 representantes de 16 instituciones y es presidido actualmente por el representante del gobierno regional de Lambayeque. En el caso de la representación de los "usuarios no agrarios" de la región Cajamarca, fue elegido el representante del sector minero entre los usuarios piscícolas, poblacional y energético. Actualmente, el CRHC ChancayLambayeque ha validado el Plan de Gestión de Recursos Hídricos ${ }^{8}$ de la cuenca con

8 Los planes de gestión de recursos hídricos en la cuenca tienen por finalidad alcanzar el uso sostenible de los recursos hídricos, así como, el incremento de las disponibilidades para lograr la satisfacción de las demandas de agua en cantidad, calidad y oportunidad, en el corto, mediano y largo plazo; en armonía con el desarrollo nacional, regional y local, articulando y compatibilizado su gestión con las políticas económicas, sociales y ambientales (Reglamento de la Ley de Recursos Hídricos, Ley $N^{\circ} 29338$ ). 
la participación de todos los usuarios y grupos de interés de la cuenca que están involucrados en la gestión del agua.

A partir de la creación y funcionamiento del CRHC Chancay-Lambayeque y la participación del sector minero en este tipo de procesos destacamos lo siguiente:

- La experiencia de los procesos de participación y representación en la cuenca a través de organizaciones de gestión es nuevo comparativamente con los procesos seguidos en otros países del continente como México y Brasil.

- La institucionalidad de este tipo de organizaciones aún requiere ser cimentada sobre la base del reconocimiento de la multisectorialidad y diversidad de usuarios que deben tener una responsabilidad compartida en la cuenca.

- La representación de los "usuarios no agrarios" en el Consejo que engloba al sector minero, energético, poblacional, piscícola, entre otros, tiende a diluirse o limitar las capacidades de participación y de representación de cada estamento, dado que los intereses son totalmente diferentes.

- La gestión del agua es un proceso institucional, técnico y social al mismo tiempo, lo cual requiere que el CRHC alcance una base amplia de participación informada, y cuente con los soportes técnicos y financieros que le permita cumplir sus funciones normadas. En ese sentido, no contar con el diseño y funcionamiento de la Secretaría Técnica aún sigue siendo una limitante para que el CRHC cumpla eficientemente su labor. La necesidad de contar con los instrumentos de gestión para el funcionamiento del CRHC dependen no sólo de la propia organización de cuenca sino también de la autoridad que los promueve, facilita y aprueba. En ese sentido, desde la experiencia del CRHC ChancayLambayeque, y en general en todos los consejos creados en el Perú, el consejo puede terminar convirtiéndose en una organización más sin los soportes que permitan desarrollar su rol y funciones.

- El rol de coordinación, concertación y de planificación que tiene el CRHC implica que los consejeros ganen en una visión de cuenca sobre la base del conocimiento directo de su territorio e internalicen este rol frente a las necesidades de afirmación de los espacios de gobernabilidad en torno a los recursos hídricos en la cuenca.

- La legitimación tanto de la organización de cuenca como del proceso que emprende debe equilibrar su sentido de autoridad en la cuenca con su capacidad para generar una visión de cuenca e interacciones con los diversos usuarios y actores sobre la base de una relación que promueva el reconocimiento y la participación de todos en la gestión de la cuenca en todas sus dimensiones (económica, productiva, ambiental, social, etc.). En el caso del CRHC ChancayLambayeque aún está en proceso la consolidación de esta legitimidad. 
- Los procesos de trabajo interinstitucional y de fortalecimiento de capacidades han sido importantes los primeros años de funcionamiento de los CRHC y requieren seguir profundizándose. En esta línea el aporte de la actividad minera, en forma coordinada, para difundir y educar en materia de aguas, sus propias intervenciones a favor de la cuenca y las intervenciones de otros actores de modo que se generen espacios de aprendizaje e intercambio, que logren al mismo tiempo, construir confianza y una simbólica en torno a la cuenca.

- La actividad minera y su correspondiente representación en la cuenca si bien muestra una política de "puertas abiertas" de sus operaciones, está llamada a tener una actuación más proactiva desde el Consejo, en términos de dar a conocer su propio funcionamiento y los aportes que realiza en la cuenca.

- La representación de los "usuarios no agrarios" cuando recae en el sector minero debe construir con los usos que representa los mecanismos de comunicación y articulación que canalice los diversos intereses de estos actores de la cuenca.

- La cuenca como realidad territorial e hidrográfica es compleja y requiere niveles de gestión que reconozca e incorpore espacios y mecanismos de gestión a menor escala (microcuencas, subcuencas). En ese sentido, las experiencias de otros países han transitado de la organización de gestión unitaria y centrada al reconocimiento normativo de organizaciones de gestión que se articulan en la cuenca desde sus distintos niveles: alta, media y baja.

\section{Reflexiones finales}

La gestión del agua en el Perú requiere de una autoridad técnica y normativa capaz de conducir no sólo los procedimientos administrativos de los derechos de uso de agua, sino también los procesos de gestión integrada de recursos hídricos para que ésta sea no sólo una mención de principio normativo sino una política hídrica nacional, en el que la intervención de todos los usuarios y actores involucrados con una visión de cuenca contribuyan en la conservación, protección y uso eficiente y sostenible del agua.

La actividad minera en los últimos años viene asumiendo un rol proactivo en los procesos de gestión del agua en la cuenca, que van más allá de los manejos de los recursos en las áreas de influencia donde realiza sus operaciones. Ciertamente, toda operación minera que cumple los estándares ambientales contribuye a la gestión del recursos hídrico en la cuenca, como captar y embalsar agua para regular la cuenca en tiempos de estiaje y ponerla al servicio de otros usos, manejar y tratar las aguas producidas en las diferentes etapas de procesamiento de minerales, proteger la calidad de las fuentes naturales de agua, entre otros. En estos aspectos observamos que la minería moderna incorpora recursos y tecnologías que protegen el ambiente. 
Pero, ¿esto es suficiente para aportar en la gestión integrada del agua?, seguro que sí. Pero, creemos que la minería puede aportar más.

Que la minería aporte más a la cuenca significa que reconociéndose parte de ella visibilice sus aportes en la cuenca, dando a conocer a los otros usuarios cómo funcionan sus operaciones y cómo éstas procuran no sólo cumplir con las normas ambientales sino también proteger y cuidar el mismo entorno natural. Ser un actor en la cuenca implica para la actividad minera, atreverse a entrar en los espacios donde hay que participar, coordinar, concertar y planificar con el Estado, otros usuarios y actores vinculados a la gestión del agua las acciones y proyectos que contribuyan al aprovechamiento eficiente y sostenible del recurso hídrico.

Ciertamente, la actividad minera posee ventajas comparativas en planificar, diseñar, proyectar, usar eficientemente, optimizar tiempos y recursos, generar y manejar información. Estas cualidades puestas al servicio de la cuenca, articuladas a las responsabilidades que tiene el Estado en materia hídrica, deben contribuir a crear o fortalecer políticas de desarrollo local y regional relacionadas al agua, sino también acciones y proyectos que hagan posible el acceso de la población al agua de calidad, a la generación y mejora de proyectos productivos vinculados al agro o la generación de energía.

\section{Bibliografía}

Benavides, R., La minería responsable y sus aportes al desarrollo del Perú, Lima, 2012, 74 pp.

Dourojeanni, A., "Los desafíos de la gestión integrada de cuencas y recursos hídricos en América Latina y el Caribe", Revista Desarrollo Local Sostenible, vol. 3, núm. 8, pp. 1-13, Eumed.net, Málaga, 2010.

Dourojeanni, A., Jouralev A. y Chávez, G., Gestión del agua a nivel de cuencas: teoría y práctica, CEPAL, Santiago de Chile, 2002, 83 pp.

Gobierno Regional de Piura-ANA-GTZ/PDRS, “Conceptos e instrumentos para la gestión integrada de cuencas hidrográficas. La experiencia de la Autoridad Autónoma de Cuenca Hidrográfica Chira-Piura”, Folleto 1, Lima, 2009, 24 pp.

Ministerio de Minería de Chile y Consejo Minero, Uso eficiente de aguas en la industria minera y buenas prácticas, Santiago de Chile, 2002.

Oficina Nacional de Diálogo y Sostenibilidad, ONDS-PCM, "Informe de diferencias, controversias y conflictos sociales”, Willaqniki, núm. 11, PCM, Lima, 2013, $62 \mathrm{pp}$. 